\title{
Inorganic Phosphate Effect of on Human Dental Pulp Cell Cultures
}

\author{
Jomana Alsenan, Laisheng Chou* \\ Email address: \\ jomana@bu.edu (J. Alsenan), Lchou@bu.edu (Laisheng Chou) \\ ${ }^{*}$ Corresponding author
}

Department of Restorative Sciences \& Biomaterials, Goldman School of Dental Medicine, Boston University, Boston, USA

\section{To cite this article:}

Jomana Alsenan, Laisheng Chou. Inorganic Phosphate Effect of on Human Dental Pulp Cell Cultures. International Journal of Materials Science and Applications. Vol. 8, No. 3, 2019, pp. 40-46. doi: 10.11648/j.ijmsa.20190803.12

Received: July 1, 2019; Accepted: August 5, 2019; Published: August 23, 2019

\begin{abstract}
This study was designed to investigate the effect of inorganic phosphate ( $\mathrm{Pi}$ ) at different concentrations on odontogenesis of the normal human dental pulp cells (hDPCs). Normal human dental pulp cells derived from extracted pristine teeth were cultured in growth medium with supplements of inorganic phosphate (Pi) in $0 \mathrm{ppm}, 2 \mathrm{ppm}, 4 \mathrm{ppm}, 5 \mathrm{ppm}$ and 8 ppm, for the time intervals of 16 hours, 7, 14, and 21 days. Cell proliferation rates were measured by the optical density of crystal violet dye stained cells. ALP activity was measured by fluorometric assay. Expression of Dentin Sialoprotein (DSP) was measured by ELISA. The data were presented as the mean of triplicates. Statistical analysis was conducted using JMP Pro 12 (ver. 12.1.0) in one-way ANOVA and Tukey HSD post-hoc tests. Cell attachment efficiency was reduced significantly by additional Pi of 2, 4 and $5 \mathrm{ppm}(P<0.05)$. At 21 days, cultures with 2, 4 and $5 \mathrm{ppm}$ supplemental Pi displayed significantly higher cell proliferation rates compared to the control group at day $14(P<0.05)$ and at day $21(P<0.05)$. At day 7 , cultures with 2, 4, 5 and $8 \mathrm{ppm}$ supplemental Pi yield significantly higher levels of ALP activity $(P<0.05)$ compared to the control group. At day 7, cultures with $5 \mathrm{ppm}$ Pi supplement showed significantly higher levels of DSP expression $(P<0.05)$ compared to the control group and the rest of the other groups. Supplemental Pi in concentration of $5 \mathrm{ppm}$ could significantly induce proliferation and odontogenesis of hDPCs. This is the first report to demonstrate Pi-induced odontogenesis, leading to potential development and clinical application of future Pi containing dental pulp capping or root canal filling materials.
\end{abstract}

Keywords: Odontogenesis, Phosphorous, Dental Pulp Cells

\section{Introduction}

Phosphorus is the second most abundant mineral in the human body. It serves the body to build and repair bones and teeth, and also helps in muscle contraction and nerve function. Phosphorus does not exist by itself in nature, as it exhibits a highly reactive characteristics [1]. It is present as phosphates in biological systems and occurs in both organic and inorganic forms. Organic forms include phospholipids that form the main structural components of all cellular membranes and various organic esters. The average adult has approximately $700 \mathrm{~g}$ of phosphate [2], which is mainly distributed in the skeleton and teeth $(85 \%)$. It is also found in soft tissue (14\%), blood $(0.3 \%)$, and extravascular fluid $(0.3 \%)$. The inorganic form exists either as free inorganic phosphate ions, or complexed with calcium, magnesium, or sodium [3, 4].

It was shown that a high-phosphate diet would significantly improve bone mineralization and play a role in formation of secondary ossification centers, but hypophosphatemia caused a delay in ossification [5]. Conversely, patients who undergo hyperphosphatemia which is a common manifestation of advanced chronic kidney disease (CKD), are disposed to cardiovascular morbidity and mortality due to increased vascular calcifications and are susceptible to bone diseases $[6,7]$.

Few studies have been conducted to test the effect of inorganic phosphate $(\mathrm{Pi})$ on osteoblasts. In some studies, it was shown that $\mathrm{Pi}$ added to culture medium acted as a specific signal for the induction of osteopontin gene expression, and ultimately protein synthesis by osteoblastlike cells [8-10]. However, most of the reports showed that osteoblast apoptosis could be activated when exposed to elevated phosphate concentrations, potentially due to profound loss of mitochondrial membrane. When exposed to 
$\mathrm{Pi}$, the osteoblast-like cells from human explants experienced a decrease in cell viability in a time- and dose-dependent manner [11]. Moreover, it was shown that $\mathrm{Ca}^{2+}$ modulated $\mathrm{Pi}$ induced osteoblast apoptosis $[12,13]$. A downregulation of osteoblast gene expression was noticed with elevated $\mathrm{Pi}$ levels in the culture medium [14].

To date, no researchers have investigated the effect of Pi on hDPCs. Accordingly, the aim of this study was to test the effect of $\mathrm{Pi}$ at different supplemented concentrations on odontogenesis of the normal human dental pulp cells (hDPCs).

\section{Materials and Methods}

\subsection{Cell Isolation and Culture}

Human dental pulp cells were isolated following the published procedure described by Stanislawski et al., with modifications [15]. The technique was employed using two third molars from a 19-year old female patient to obtain the hDPCs, through proper informed consent before extraction at the oral surgery department of Boston University School of Dental Medicine. Briefly, teeth were sagitally scored with a high-speed hand piece and 330 bur without entering the pulp chamber. Using a bi-bevel chisel, teeth were sectioned and fresh dental pulp tissue was collected immediately. The pulp tissue was then dissected into small pieces and placed into 25 $\mathrm{ml}$ flasks containing culture medium which was subsequently maintained in a humidified atmosphere at $37^{\circ} \mathrm{C}$ with $5 \%$ $\mathrm{CO}_{2}$. Culture medium consisted of Eagle's Basal Medium (BME) (Gibco), with supplements of $10 \%$ fetal bovine serum (Atlanta Biologicals), $100 \mathrm{U} / \mathrm{mL}$ of penicillin G (Gibco), 100 $\mathrm{mg} / \mathrm{mL}$ streptomycin (Gibco), and $2.5 \mathrm{mg} / \mathrm{mL}$ amphotericinB (Gibco). Culture medium was replaced every three days. Upon confluence, the cells were trypsinized $(0.05 \%$ trypsin, Life Technologies) and transferred into $250 \mathrm{ml}$ flasks in medium as described above. When cells again reached confluence, they were trypsinized and subsequently counted with a hemocytometer (Reichert-Jung) under a microscope as described by Freshney [16]. Cells were suspended at $3 \times 10^{3}$ per $\mathrm{ml}$ and transferred to 24 -well plates and cultured. At that stage, cells were immediately used for seeding in medium containing 0 ppm, 2 ppm, 4 ppm, 5 ppm and 8 ppm of $\mathrm{Pi}$ as sodium phosphate $\left[\mathrm{Na}_{3} \mathrm{PO}_{4}\right]$, dibasic, anhydrous (Fisher Biotech). Under sterile conditions, $\mathrm{Na}_{3} \mathrm{PO}_{4}$ was added to the culture medium and was sterilized via $0.2 \mu \mathrm{m}$ filtration.

\subsection{Measurement of Cell Attachment and Proliferation}

Three thousand normal human dental pulp cells were seeded in each well of the 24 -well plates (Fisher Scientific) containing $1 \mathrm{~mL}$ medium with different supplemented $\mathrm{Na}_{3} \mathrm{PO}_{4}$ concentrations as described above. Each condition was prepared in triplicate and incubated for 16 hours in an incubator (saturated humidity, $37^{\circ} \mathrm{C}, 5 \% \mathrm{CO}_{2}$ ). At 16 hours, cell attachment was quantified through direct cell counts of floating cells using a hemocytometer (Reichert-Jung) and normalized to the initial cell seeding density.

Cell proliferation studies were determined at 7,14 and 21 days. Culture medium was aspirated, plates were rinsed twice with $1 \mathrm{X}$ PBS and then cells were fixed with $1 \mathrm{ml} 10 \%$ neutral buffered formalin (Sigma) for one hour at room temperature (RT). Fixer solution was then discarded and plates were washed twice with $1 \mathrm{X}$ PBS and stained with 1 $\mathrm{ml} 0.2 \%$ crystal violet stain (Sigma Aldrich) for 1 hour at RT [17]. Unbound stain was removed by rinsing plates thoroughly with deionized water until the rinse was clear. Then, optical density (O.D) value was measured by a microplate reader (TECAN, Infinite 200 Pro) at a wavelength of $590 \mathrm{~nm}$. Absorbance of crystal violet is directly proportional to cell numbers.

\subsection{Screening of Odontoblast Phenotypic Markers}

For differentiation studies, growth medium were replaced with pre-odontogenic inductive medium 48-hours before each predetermined time point, i.e. days 7, 14 and 21. Preodontogenic medium consists of $10 \%$ charcoal stripped fetal bovine serum FBS (Gibco), $100 \mathrm{U} / \mathrm{mL}$ Penicillin G (Gibco), $100 \mathrm{mg} / \mathrm{mL}$ Streptomycin (Gibco), $10^{-8} \mathrm{M}$ Menadione (Sigma Aldrich), $10 \mathrm{mM} \beta$-Glycerophosphate (Sigma Aldrich), 1.5 mg L-ascorbic acid (Sigma Aldrich), and $2 \mathrm{mM}$ L-glutamine (Fisher Scientific) in BME medium (Gibco). Again, under sterile conditions, $\mathrm{Pi}$ was added to the pre-odontogenic inductive medium in concentrations of 0 ppm, $2 \mathrm{ppm}, 4 \mathrm{ppm}$, $5 \mathrm{ppm}$ and $8 \mathrm{ppm}$ of $\mathrm{Na}_{3} \mathrm{PO}_{4}$. The medium were then sterilized via $0.2 \mu \mathrm{m}$ filtration. Cell culture plates at 6,13 and 20 days, were cultured for an additional 24-hours in fresh pre-odontogenic inductive medium to which was added 10 nM VitD3 (Sigma). The supernatant fluid was collected at days 7, 14 and 21. ALP activity and DSP production were measured from the collected supernatants. The odontogenesis phenotype was confirmed by adding VitD3.

\subsection{Measurement of Alkaline Phosphatase (ALP) Activity}

Alkaline phosphatase activity was measured with ALP fluorometric assay kit (Abcam) according to the manufacturer's instructions. Each well of a 96 well black plate with clear bottom (Thermo Scientific) received $100 \mu \mathrm{L}$ culture supernatant and $20 \mu \mathrm{L}$ of the non-fluorescent 4methylumbelliferone phosphatase disodium salt (MUP) substrate. The plate was subsequently incubated for 30 minutes at $25^{\circ} \mathrm{C}$ in the dark. During that time, MUP substrate was dephosphorylated to the fluorescent 4methymbelliferone by active ALP obtained in supernatants. The enzymatic reaction was then stopped with $20 \mu \mathrm{L}$ stop solution. Emissions of the fluorescent substrate were measured at $440 \mathrm{~nm}$ using a microplate reader (TECAN, Infinite 200 Pro). The enzymatic activity was calculated according to the standard curve generated.

\subsection{Measurement of Dentin Sialoprotein (DSP)}

Dentin sialoprotein expression levels were determined by the competitive Dentin Sialoprotein (BioAssay ${ }^{\mathrm{TM}}$ ) enzymelinked immunosorbent assay kit (Human), (US Biologicals) in $100 \mu \mathrm{L}$ supernatants following the manufacturer's 
instructions. Cell culture supernatants were centrifuged to remove debris. Triplicate samples and standards were initially mixed with $100 \mu \mathrm{L}$ of balance buffer and incubated with $50 \mu \mathrm{L}$ DSP-HRP conjugate for 1 hour at $37^{\circ} \mathrm{C}$. Then wells were washed five times and incubated with $100 \mu \mathrm{L}$ substrate for HRP enzyme for 15 minutes in the dark at room temperature. Finally, $50 \mu \mathrm{L}$ of stop solution was added, which turned the solution color from blue to yellow. The intensity of the solution color was measured at $450 \mathrm{~nm}$ in a microplate reader (TECAN, Infinite 1000 Pro). A standard curve was plotted relating the intensity of the color (O.D) to the concentrations of the standards.

\subsection{Statistical Analysis}

All experiments were performed in triplicate and the differentiation data was normalized on a per million cells basis. Statistical analysis was performed using JMP Pro 12 (ver. 12.1.0) in one-way variance statistical analysis with the Tukey multiple comparison post hoc test. Differences were considered significant at $P \leq 0.05$.

\section{Results}

\subsection{Attachment Efficiency Affected by Pi at Various Concentrations}

Groups supplemented with 2, 4 and 5 ppm of Pi showed significantly lower attachment efficiency $(P<0.05)$ when compared to the control group (Figure 1). The $8 \mathrm{ppm} \mathrm{Pi}$ group displayed no significant difference in comparison to the control group. However, the 8 ppm Pi group exhibited higher attachment efficiency compared to the 2, 4 and $5 \mathrm{ppm}$ Pi groups $(P<0.05)$.

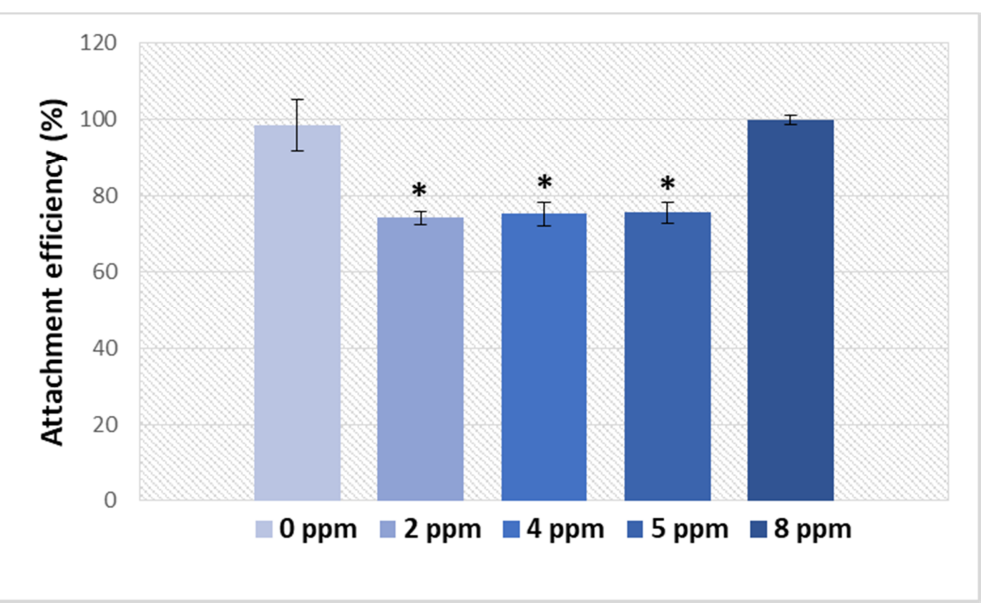

Figure 1. Attachment efficiency of human dental pulp cells in medium supplemented with various concentrations of Pi for 16 hours. $(* P \leq 0.05)$.

\subsection{Proliferation Rate Affected by Pi at Various Concentrations}

The proliferation rates of hDPCs cultured with different concentrations of Pi were determined by the crystal violet dye technique at days 7,14 and 21. The starting point of the experiment was the 16 hour attachment study. At day 7
(Figure 2), a significant cell number increase was observed in the Pi groups of 4 and 5 ppm $(P<0.05)$ only. However, at 14 and 21 days, a significant increase in cell number was observed in the Pi groups containing 2, 4 and 5 ppm $(P<0.05)$ compared to the control group. With highest proliferation rates attributed to Pi group of $5 \mathrm{ppm}$.

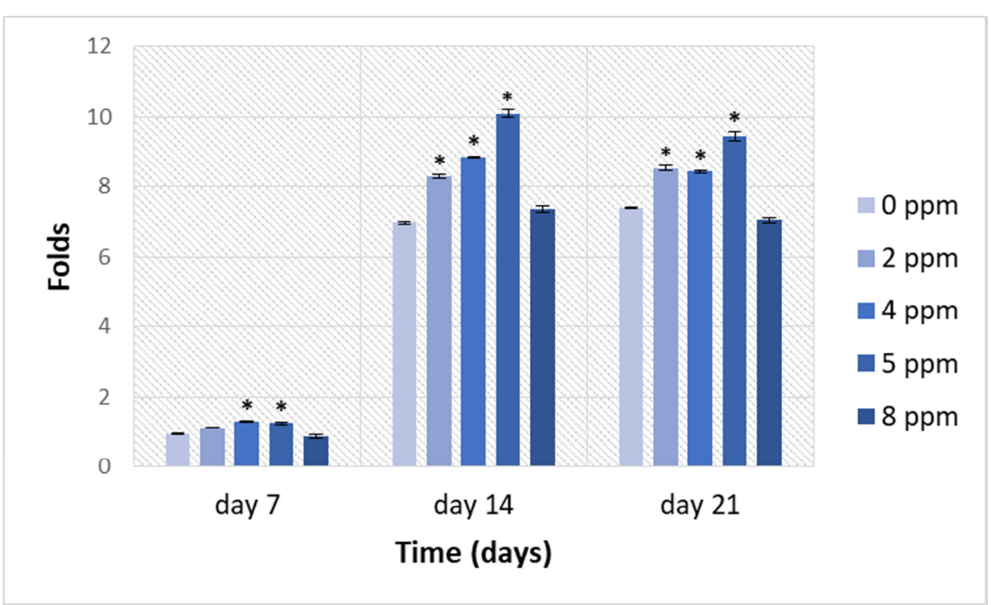

Figure 2. Proliferation of human dental pulp cells in medium supplemented with various concentrations of Pi for time intervals of 7,14 and 21 days. $(* P \leq 0.05)$. 


\subsection{ALP Activity Affected by Pi at Various Concentrations}

Figure 3 shows the ALP activity for cells grown in medium supplemented with Pi in various concentrations. At day 7 a significant increase in ALP activity for all supplemented groups $(P<0.05)$ was observed compared to the control group.
However, at day 14 , the ALP activity in general dropped to lower levels. Thus, the $4 \mathrm{ppm}$ supplement group was the only group showing significant value compared to the control group $(P<0.05)$. At day 21, ALP activity overall dropped even more, with no significant differences among all groups.

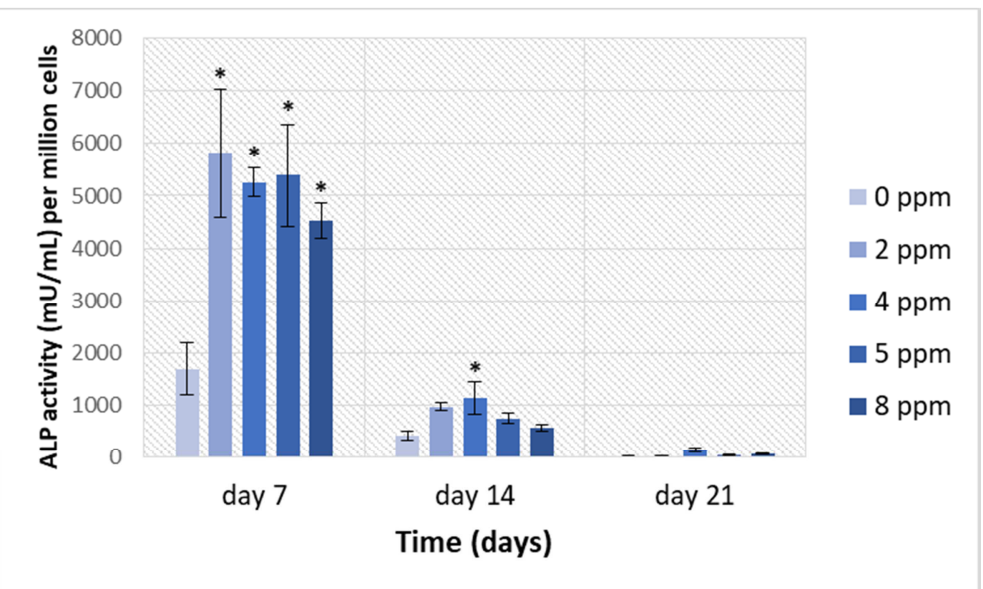

Figure 3. Alkaline phosphatase activity of human dental pulp cells in medium supplemented with various concentrations of Pi for time intervals of 7,14 and 21 days. $(* P \leq 0.05)$

\subsection{DSP Production Affected by Pi at Various Concentrations}

An ELISA Assay was utilized to measure the secreted dentin sialoprotein in the hDPCs cultures. At day 7 the highest values of secreted DSP were derived from cells exposed to supplemented $\mathrm{Pi}$ of $5 \mathrm{ppm}$ compared to the control $(P<0.05)$ (Figure 4). Groups of 2 and 4 ppm displayed levels comparable to DSP expression in the control group. However, the Pi 8 ppm group exhibited significantly lower value compared to the control group $(P<0.05)$. As in the ALP activity test, at day 14 DSP overall activity dropped to lower levels. The groups with 2 and 4 ppm supplements were the only groups that displayed significant values compared to the control group $(P<0.05)$. At day 21 , the DSP overall level dropped even more, with no significant differences among all groups.

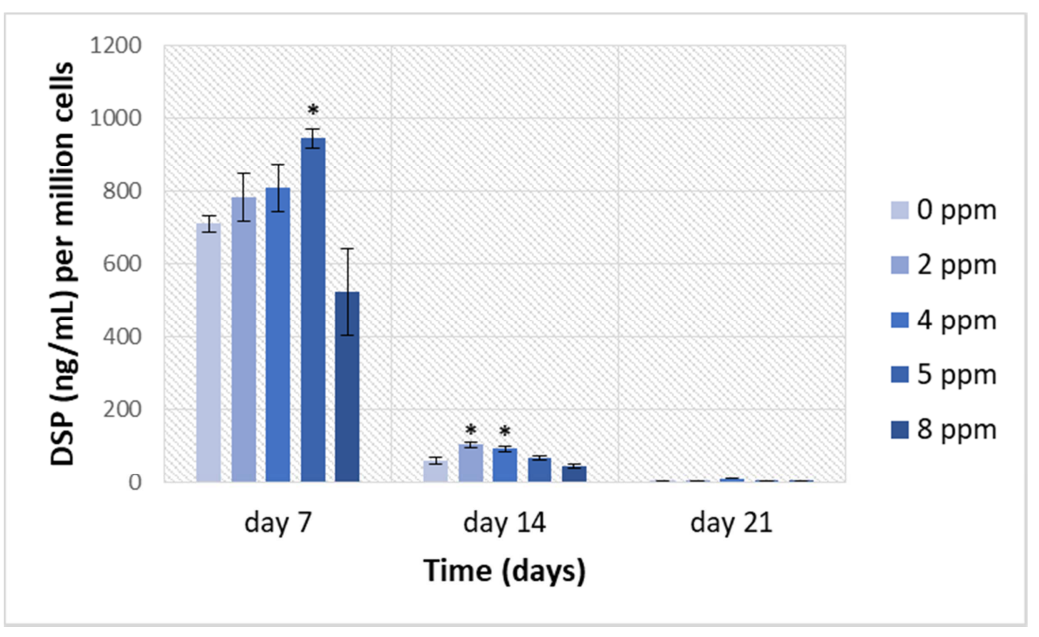

Figure 4. Dentin sialoprotein expression of human dental pulp cells in medium supplemented with various concentrations of Pi for time intervals of 7, 14 and 21 days. $(* P \leq 0.05)$.

\section{Discussion}

Inorganic phosphate is an essential nutritional element supporting skeletal development, metabolic processes and energy production [18]. Moreover, it serves as an important component of DNA, RNA, cellular membrane phospholipids and cell-signaling intermediate. The aim of the present study was to evaluate the odontogenic effect of various concentrations of supplemented $\mathrm{Pi}$ on normal hDPCs cultures. Taking into consideration the $140 \mathrm{ppm}$ of $\mathrm{Pi}$ supplemented in the BME culture medium, which reflects the physiological concentration existing in the human body, any 
supplementary amount in this study would be in addition to what already exists in the culture medium. Genetically, the odontoblast and osteoblast cell profiles are almost identical [19]. However, there is a clear difference in cellular morphology between bone and dentin.

Until now, there are no reports demonstrating the effect of Pi ions on the hDPCs cultures. In this study, cell attachment efficiency, proliferation rate, alkaline phosphatase activity and dentin sialoprotein expression were investigated on the hDPCs cultures.

Several studies indicated that the surface topography of substrata was a key factor effecting cell attachment efficiency [20-22]. It has been observed in the current study that within the 16 hour time period, no cell doubling occurred. Therefore possible cell number changes are solely attributed to the ability of hDPCs to attach to culture wells when grown in culture medium containing different $\mathrm{Pi}$ concentrations. The results demonstrated a significant down regulation tendency in groups at 2, 4 and $5 \mathrm{ppm}$, but the exact mechanism and precise role of $\mathrm{Pi}$ is not clear.

A report on rat bone marrow cells showed an inhibitory effect of Pi on proliferation [23]. In that study, rat bone marrow cells were cultured with various bioglasses and inhibition of cell proliferation seemed to be related to a high phosphate-ion release or phosphorus-rich precipitations. In the current study, hDPCs did not behave like the rat cells. Instead, a significant upregulation of cells proliferation in all groups containing supplemented $\mathrm{Pi}$ was observed. This indicates that supplemented $\mathrm{Pi}$ can be beneficial to the growth of hDPCs. An exception manifests itself with the high concentration Pi group (8 ppm), which exhibited almost an equal proliferation rates compared to the control group. This can be explained by the fact that osteoblast apoptosis can be activated when cells have been exposed to elevated phosphate concentrations, potentially due to the profound loss of mitochondrial membrane. Reports showed that when exposed to different $\mathrm{Pi}$ concentrations, the osteoblast-like cells from human explants exhibited reduced cell viability in a time- and dose-dependent manner [11].

One study examined the effect of concentration of both calcium and phosphorous on osteogenesis. UMR 106-01 BSP cells were treated with calcium $(\mathrm{Ca})$ for 24 hours with or without the addition of Pi supplement [24]. Results of the study showed a Ca-dependent increase in mineral formation. However, cultures without an additional Pi supplement only formed detectable mineral at a relatively high $\mathrm{Ca}$ concentration. Cultures treated with low $\mathrm{Ca}$ and high $\mathrm{Pi}$ concentrations produced nearly twice as much calcium mineral as those exposed to high $\mathrm{Ca}$ and low $\mathrm{Pi}$ concentrations. Moreover, the addition of organophosphates (typically $\beta$-glycerophosphate) to cultures of primary osteoblast cells enhanced the formation of calcium mineral. In this case, ALP is required to hydrolyze the organophosphates to release $\mathrm{Pi}$ which appears to be the actual initiator of mineral formation. Therefore, increased Pi seems to initiate a mineral formation that afterward is enhanced by Ca levels. However, we cannot exclude the possibility that a portion of the mineral formed in these cultures might be the result of a direct heterogeneous nucleation within the established extracellular matrix of the cell layer.

Pyrophosphate is present in the extracellular matrix of most tissues and is a by-product of many intracellular metabolic reactions, acting as a mineralization inhibitor in bone $[25,26]$. Meanwhile, the function of ALP and ATPase are also involved in the transport of $\mathrm{Pi}$ and $\mathrm{Ca}$ by increasing the local concentration of $\mathrm{Pi}$ while removing the pyrophosphate inhibitors of apatite deposition [27]. In our study, the presence of supplemental Pi led to increased levels of ALP expression in hDPCs cultures. Alkaline phosphatase activity was significantly high in all Pi supplemented groups and the remarkable peak of ALP expression was reached at day 7 , but then declined radically at 14 and 21 days. This phenomena is elucidated by the inverse relationship between proliferation and differentiation [28]. This high ALP activity which was reached at day 7 , is mostly attributed to the fact that ALP occurs in the early stages of differentiation [29].

Dentin sialoprotein was significantly higher in the $5 \mathrm{ppm}$ supplemented Pi group in the current study. This masks the fact that supplemented $\mathrm{Pi}$ at $5 \mathrm{ppm}$ has less effect on inducing hDPCs differentiation into odontoblast-like cells than other groups. Dentin sialophosphoprotein (DSPP) gets cleaved into DSP by the terminally differentiated odontoblasts to prompt mineralization and dentinogenesis [30]. DSP is an important marker for dentin production since it is produced only by mature odontoblast cells and has not been found in other cells $[31,32]$. As with the ALP study, the DSP results showed summiting of DSP levels at day 7 . Subsequently the expression gets noticeably reduced at 14 and 21 days. To identify the relationship of phosphate and mineralization, in a previous in vitro study on rat bone, cell cultures were maintained in medium containing ascorbic acid after day 7 and lacking the organic phosphate source, $\beta$ glycerophosphosphate ( $\beta$-GP) [33]. Under accelerated mineralizing conditions (with $\beta-\mathrm{GP}$ ), osteocalcin mRNA synthesis increased steadily beginning at day 15 in parallel with $\mathrm{Ca}$ accumulation in the cell layer. In contrast, when cultures were maintained in the absence of $\beta$-GP, Ca did not begin to accumulate in the cell layer until day 25 . Osteocalcin was not detectable until this point. Its low level of synthesis reflects the slower rate of mineralization. However, the presence or absence of $\beta$-GP had no effect on the proliferation period or on the onset of ALP expression. Taken together, it can be concluded that $\mathrm{Pi}$ at $5 \mathrm{ppm}$ supplemented concentration would produce the most proliferation and differentiation up-regulation.

\section{Conclusion}

This study demonstrated that $\mathrm{Pi}$ at $5 \mathrm{ppm}$ could significantly induce proliferation and odontogenesis of hDPCs. This is the first report to demonstrate the optimal Pi concentration for inducing human odontogenesis, which may lead to potential development of clinical applications using dental-pulp related biomaterials. More importantly, the current study tested 
normal human dental pulp cells in vitro and has set a landmark for future studies. For instance, micro-molecular investigations are required to understand the cellular functions of $\mathrm{Pi}$. Furthermore, the reported optimal Pi concentration needs to be verified using in vivo studies as well with optimal concentration of Pi released from implanted material having various degradation rates. The generated results of the current study are essential when manufacturing Pi-containing biomaterials for dental-pulp complex tissue regeneration.

\section{Conflict of Interest}

The authors deny any conflicts of interest related to this study.

\section{References}

[1] Williams R. Phosphorus biochemistry. 1978.

[2] Del Valle HB, Yaktine AL, Taylor CL, Ross AC. Dietary reference intakes for calcium and vitamin D: National Academies Press; 2011.

[3] Iheagwara OS, Ing TS, Kjellstrand CM, Lew SQ. Phosphorus, phosphorous, and phosphate. Hemodialysis International. 2013; 17: 479-82.

[4] Hong S-H, Park S-J, Lee S, Kim S, Cho M-H. Biological effects of inorganic phosphate: potential signal of toxicity. The Journal of Toxicological Sciences. 2015; 40: 55-69.

[5] Zhang R, Lu Y, Ye L, Yuan B, Yu S, Qin C, et al. Unique roles of phosphorus in endochondral bone formation and osteocyte maturation. Journal of Bone and Mineral Research. 2011; 26: 1047-56.

[6] Hsu Y-J, Hsu S-C, Huang S-M, Lee H-S, Lin S-H, Tsai C-S, et al. Hyperphosphatemia induces protective autophagy in endothelial cells through the inhibition of Akt/mTOR signaling. Journal of Vascular Surgery. 2015; 62: 210-21.e2.

[7] Nadkarni GN, Uribarri J. Phosphorus and the Kidney: What Is Known and What Is Needed. Advances in Nutrition. 2014; 5: 98-103.

[8] Beck GR, Zerler B, Moran E. Phosphate is a specific signal for induction of osteopontin gene expression. Proceedings of the National Academy of Sciences. 2000; 97: 8352-7.

[9] Beck GR, Moran E, Knecht N. Inorganic phosphate regulates multiple genes during osteoblast differentiation, including Nrf2. Experimental cell research. 2003; 288: 288-300.

[10] Beck GR. Inorganic phosphate as a signaling molecule in osteoblast differentiation. Journal of cellular biochemistry. 2003; 90: 234-43.

[11] Meleti Z, Shapiro I, Adams CS. Inorganic phosphate induces apoptosis of osteoblast-like cells in culture. Bone. 2000; 27: 359-66.

[12] Adams CS, Shapiro I. Mechanisms by which extracellular matrix components induce osteoblast apoptosis. Connective tissue research. 2003; 44: 230-9.

[13] Adams CS, Mansfield K, Perlot RL, Shapiro IM. Matrix regulation of skeletal cell apoptosis role of calcium and phosphate ions. Journal of Biological Chemistry. 2001; 276:
20316-22.

[14] Gupta G, Kirakodu S, El-Ghannam A. Effects of exogenous phosphorus and silicon on osteoblast differentiation at the interface with bioactive ceramics. Journal of Biomedical Materials Research Part A. 2010; 95A: 882-90.

[15] Stanislawski L, Carreau JP, Pouchelet M, Chen ZHJ, Goldberg M. In vitro culture of human dental pulp cells: some aspects of cells emerging early from the explant. Clinical Oral Investigations. 1997; 1: 131-40.

[16] Freshney RI. Culture ofanimal cells. A Manual ofBasic. 1994.

[17] Chou L, Firth JD, Nathanson D, Uitto V-J, Brunette DM. Effects of titanium on transcriptional and post-transcriptional regulation of fibronectin in human fibroblasts. Journal of Biomedical Materials Research. 1996; 31: 209-17.

[18] Takeda E, Yamamoto H, Nashiki K, Sato T, Arai H, Taketani Y. Inorganic phosphate homeostasis and the role of dietary phosphorus. Journal of Cellular and Molecular Medicine. 2004; 8: 191-200.

[19] Ariffin S, Manogaran T, Abidin I, Wahab R, Senafi S. A Perspective On Stem Cells As Biological Systems That Produce Differentiated Osteoblasts And Odontoblasts. Current stem cell research \& therapy. 2016.

[20] Chou L, Firth JD, Uitto V-J, Brunette DM. Substratum surface topography alters cell shape and regulates fibronectin mRNA level, mRNA stability, secretion and assembly in human fibroblasts. Journal of Cell Science. 1995; 108: 1563-73.

[21] Chou L, Firth JD, Uitto VJ, Brunette DM. Effects of titanium substratum and grooved surface topography on metalloproteinase - 2 expression in human fibroblasts. Journal of biomedical materials research. 1998; 39: 437-45.

[22] Keller JC, Collins JG, Niederauer GG, McGee TD. In vitro attachment of osteoblast-like cells to osteoceramic materials. Dental Materials. 1997; 13: 62-8.

[23] Knabe C, Gildenhaar R, Berger G, Ostapowicz W, Fitzner R, Radlanski R, et al. Morphological evaluation of osteoblasts cultured on different calcium phosphate ceramics. Biomaterials. 1997; 18: 1339-47.

[24] Stanford CM, Jacobson PA, Eanes ED, Lembke LA, Midura RJ. Rapidly forming apatitic mineral in an osteoblastic cell line (UMR 10601 BSP). Journal of Biological Chemistry. 1995; 270: 9420-8.

[25] Addison WN, Azari F, Sørensen ES, Kaartinen MT, McKee MD. Pyrophosphate inhibits mineralization of osteoblast cultures by binding to mineral, up-regulating osteopontin, and inhibiting alkaline phosphatase activity. Journal of Biological Chemistry. 2007; 282: 15872-83.

[26] Fleish H, Neuman WF. Mechanisms of calcification: role of collagen, polyphosphates, and phosphatase. American Journal of Physiology--Legacy Content. 1961; 200: 1296-300.

[27] Boskey A, Posner A. Optimal conditions for Ca-acidic phospholipid-PO4 formation. Calcified tissue international. 1981; 34: S1-7.

[28] Yang X, van den Dolder J, Walboomers XF, Zhang W, Bian Z, Fan M, et al. The odontogenic potential of STRO-1 sorted rat dental pulp stem cells in vitro. Journal of Tissue Engineering and Regenerative Medicine. 2007; 1: 66-73. 
[29] Väkevä L, Mackie E, Kantomaa T, Thesleff I. Comparison of the distribution patterns of tenascin and alkaline phosphatase in developing teeth, cartilage, and bone of rats and mice. The Anatomical Record. 1990; 228: 69-76.

[30] Kim J, Song Y-S, Min K-S, Kim S-H, Koh J-T, Lee B-N, et al. Evaluation of reparative dentin formation of ProRoot MTA, Biodentine and BioAggregate using micro-CT and immunohistochemistry. Restorative Dentistry \& Endodontics. 2016; 41: 29-36.

[31] Butler WT, Bhown M, Brunn JC, D'Souza RN, Farach-Carson $\mathrm{MC}$, Happonen R-P, et al. Isolation, Characterization and Immunolocalization of a 53-kDal Dentin Sialoprotein (DSP). Matrix. 1992; 12: 343-51.
[32] Couble M-L, Farges J-C, Bleicher F, Perrat-Mabillon B, Boudeulle M, Magloire H. Odontoblast Differentiation of Human Dental Pulp Cells in Explant Cultures. Calcified Tissue International. 2000; 66: 129-38.

[33] Owen TA, Aronow M, Shalhoub V, Barone LM, Wilming L, Tassinari MS, et al. Progressive development of the rat osteoblast phenotype in vitro: reciprocal relationships in expression of genes associated with osteoblast proliferation and differentiation during formation of the bone extracellular matrix. Journal of cellular physiology. 1990; 143: 420-30. 